International Journal of Environmental Research and

Public Health

ISSN 1660-4601

www.mdpi.com/journal/ijerph

Correction

\title{
Correction: Song, J.; Yang, X.; Zhang, J.; Long, Y.; Zhang, Y.; Zhang, T. Assessing the Variability of Heavy Metal Concentrations in Liquid-Solid Two-Phase and Related Environmental Risks in the Weihe River of Shaanxi Province, China. Int. J. Environ. Res. Public Health 2015, 12, 8243-8262.
}

\author{
Jinxi Song ${ }^{1,2, *}$, Xiaogang Yang ${ }^{2}$, Junlong Zhang ${ }^{2}$, Yongqing Long ${ }^{2}$, Yan Zhang ${ }^{2}$ and \\ Taifan Zhang ${ }^{2}$
}

1 State Key Laboratory of Soil Erosion and Dryland Farming on the Loess Plateau, Institute of Soil and Water Conservation, Chinese Academy of Sciences, Yangling 712100, China

2 College of Urban and Environmental Sciences, Northwest University, Xi' an 710027, China; E-Mails:yxgyff166@163.com(X.Y.);junlongzhangcq@hotmail.com(J.Z.); sjzxlyq@nwu.edu.cn(Y.L.); zhangy.11b@igsnrr.ac.cn(Y.Z.); zhangtaifan@163.com(T.Z.)

* Author to whom correspondence should be addressed; E-Mail: jinxisong@nwu.edu.cn; Tel./Fax: +86-29-8830-8596.

Academic Editors: Paul B. Tchounwou and Kiran Tota-Maharaj

Received: 2 November 2015 / Accepted: 3 November 2015 / Published: 12 November 2015

The authors wish to make the following corrections to this paper [1].

In the Acknowledgments Section, the sentence "This work was support by National Natural Science Foundation of China (Grant No.51379715)" should read as follows:

\section{Acknowledgments}

This work was supported by the National Natural Science Foundation of China (Grant No.51379175); Specialized Research Fund for the Doctoral Program of Higher Education (Grant No.20136101110001); Program for Key Science and Technology Innovation Team in Shaanxi Province (Grant No. 2014KCT-27); and Program for New Century Excellent Talents in University (Grant No. NCET-11-1045). We thank Jiaxuan Li, Xiaojuan Li and other members for their assistance in field sampling and laboratory experiments. 
The authors would like to apologize for any inconvenience caused to the readers by this change. The manuscript will be updated and the original will remain available from the article webpage.

\section{Reference}

1. Song, J.; Yang, X.; Zhang, J.; Long, Y.; Zhang, Y.; Zhang, T. Assessing the Variability of Heavy Metal Concentrations in Liquid-Solid Two-Phase and Related Environmental Risks in the Weihe River of Shaanxi Province, China. Int. J. Environ. Res. Public Health 2015, 12, 8243-8262.

(C) 2015 by the authors; licensee MDPI, Basel, Switzerland. This article is an open access article distributed under the terms and conditions of the Creative Commons Attribution license (http://creativecommons.org/licenses/by/4.0/). 